Check for updates

Berlin

hristio@yahoo.com

Cite this as: BMJ 2021;375:n2412

http://dx.doi.org/10.1136/bmj.n2412

Published: 5 October 2021

\section{Covid-19: Why the Balkans' vaccine rollout lags behind most of Europe}

\section{Europe's successful vaccine rollout has not extended to the east of the continent. Hristio Boytchev asks what's been holding the Balkan countries back}

\section{Hristio Boytchev freelance journalist}

If Irina Hristova gets covid-19, she might die, she says. The 66 year old lives with her husband in a village in the Balkan Mountains, two hours east of Bulgaria's capital Sofia. She avoids crowds but can't completely isolate herself. Hristova watches her grandchildren when they are sent home from school with colds or during school holidays and lockdowns.

Hristova has a chronic lung condition that requires regular treatment, putting her among those at highest risk from covid-19. Yet she has no plans to get a vaccine, even though she could immediately get an appointment. Hristova worries about the possible side effects on her frail immune system and has general doubts about the safety of the vaccines. When she asked her doctor for advice, he referred her to a rheumatologist in a city over an hour away.

Hristova is far from being an exception. As of 20 September, less than $19 \%$ of Bulgaria's population have been fully vaccinated against covid-19-the lowest rate in the European Union, where the average is $61 \%$.

There is no single reason why. It is a combination of local idiosyncrasies and concerns shared globally. As in other parts of the world, the common motif is trust.

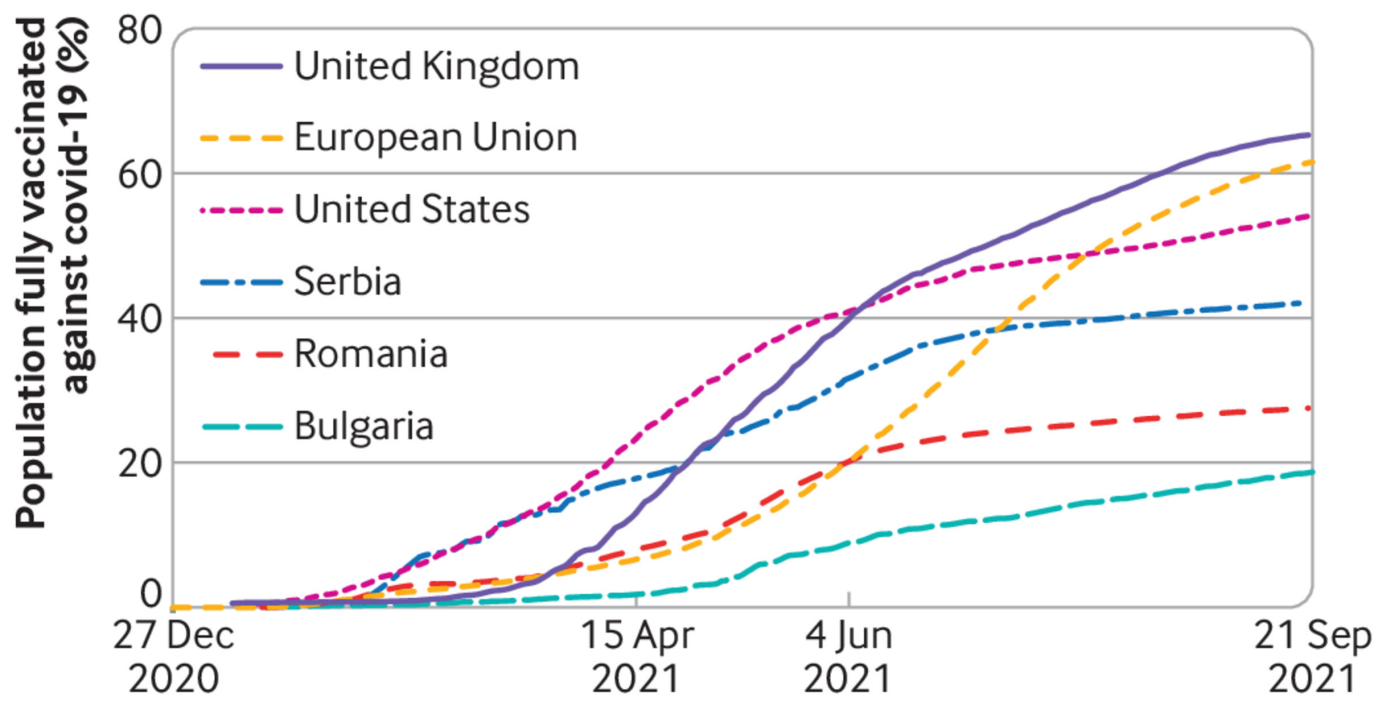

\section{Distrust}

In Bulgaria, many had little trust in the authorities to begin with. The government that has led the country throughout most of the pandemic has been plagued by corruption scandals, leading to months long protests calling for preterm elections.

A large percentage of Bulgarians distrust institutions, says Kosta Kostov, a pulmonology consultant at Sofia's Sveta Anna university hospital. He views the low vaccination numbers as "a protest vote against years of authoritarian rule.”

The beginning of the pandemic was marked by low incidence of covid-19 compared with the rest of the EU. The Bulgarian government responded, however, with hard containment measures, some of them disproportionate, according to Mariya Sharkova, a medical lawyer in Sofia.

Roads were blocked, requiring special permission to travel between provinces, and natural parks like the
Vitosha Mountains, a popular hiking destination, were closed. When the measures were then abruptly lifted in the summer of 2020, people remained largely unconvinced of the epidemic's danger, Sharkova says.

The government then failed to prepare for the winter, when the pandemic hit heavily. Testing services were overwhelmed, with over $40 \%$ of all tests carried out in November 2020 coming back positive. The government was again criticised, this time for failing to enforce quarantine and masking orders.

During that period, access to medical services was overwhelmed, outpatient care in particular. "Patients had no access to medical care except over the phone with a general practitioner," Sharkova says. For safety reasons, simple blood tests, $\mathrm{x}$ rays, and scans were referred to hospitals-many of which were exclusively treating covid patients. Others refused covid patients, putting a strain on emergency services. 
"Access to outpatient care depended entirely on whether the patient's GP had organised their work adequately and was able to cover all their patients," says Sharkova. Some patients had to wait over 24 hours for an ambulance to arrive, Sharkova says.

In this situation, many patients chose not to report health problems or delayed examinations, worsening chronic conditions. Nina Yancheva, head of the infectious diseases department at the Medical University of Sofia, says patients were being admitted to hospital late, already severely ill, and requiring intensive care, which contributed to high overall mortality.

This lack of coordination and long term planning has likely contributed to Bulgaria having one of the highest covid mortalities in Europe. By the end of August, cumulative official deaths from covid-19 were more than 2700 per 100 ooo, one of the highest rates in the EU, which averages around 1700 per 100 ooo. ${ }^{1}$ Excess mortality per capita temporarily spiked to the highest in the world in November and December 2020, with weekly deaths more than twice the historical average, and is cumulatively the second highest in the world after Peru. ${ }^{2}$

The government needed a successful vaccination campaign both to save lives and save face, but the scandals continued. "The vaccine campaign started out as a joke,” says Desislava Nikolova, health reporter for the Bulgarian magazine Capital. Nikolova reported that Bulgaria hadn't originally ordered Pfizer Biontech and Moderna vaccines through the joint EU framework, thereby forfeiting access to the vaccines first approved in the EU. Even when Bulgaria updated its order, the gaffes kept coming. The first shipments of Pfizer vaccines were delivered in trucks normally carrying sausages, prompting ridicule and internet memes of sausages with syringes.

Despite the stumbles, the beginning of the vaccine rollout was met by demand that far exceeded supply. But the delays and overreliance on AstraZeneca jabs meant that by the end of January, Bulgaria had administered less than 0.6 vaccine doses per capita, less than one fifth the EU average and the number in neighbouring Romania. This meant that when public interest in vaccines was highest, supply was lowest, says Iva Christova, director of the National Centre of Infectious and Parasitic Diseases.

Some of the vaccines were apparently distributed to the wrong recipients. Bulgaria officially prioritised health workers and the elderly, but government officials and employees of large companies were also among the first to boast of being vaccinated. Corruption scandals-virtually omnipresent in Bulgaria-had unmistakably reached vaccine policy.

In addition, Bulgaria's institutions have not found an efficient way to counter misinformation on social media, says Christova.

Doctors have played an ambiguous role. Some well known doctors have expressed hesitancy about vaccines. A bigger concern is that, at the end of July, only $63 \%$ of doctors were fully

vaccinated ${ }^{3}$-although the low figure could partly be because many doctors were ineligible after an infection (according to the Bulgarian ministry of health, the first dose of the vaccine should not be given earlier than three months after an infection, the second dose not earlier than six months after an infection after the first dose).

\section{Elsewhere in south eastern Europe}

Bulgaria's neighbours have slightly higher vaccination rates but share its structural problems.

In Serbia, the government's response has been erratic. The authorities resorted to draconian measures at the start of the pandemic, isolating people over 65 for six weeks and letting them leave the house only on Saturday mornings, says Zoran Radovanović, a retired epidemiologist in Belgrade. Then, in May 2020, martial law and curfews were suddenly abandoned. Cases had started to drop by that time, but Radovanović thinks the decision had more to do with elections scheduled for June.

The pandemic was characterised by the government's desire to present a positive picture, he says, even skewing the statistics. When figures on overall excess mortality were released, it became clear that the true number of deaths was more than twice as high as originally counted, Radovanović told The BMJ. An analysis counts almost 31 ooo additional deaths during the pandemic-the fifth highest in the world per capita and four times the number officially attributed to covid-19. ${ }^{4}$

Vaccinations, on the other hand, got off to a quick start in Serbia. Outside the EU, the country is not bound by the decisions of the European Medical Agency and chose to authorise and import vaccines from Russia and China. "The point was to impress the world by obtaining an abundant supply," says Radovanović.

By mid-February, Serbia had vaccinated three times more people than the EU average. But take-up has slowed since June, attributed to a combination of poor government communication and vaccine sceptics appearing prominently in the media. At the time of writing around $42 \%$ of the population had been fully vaccinated.

Romania, too, went overboard with initial measures that were suddenly abandoned when the rates slowed, says Andrei Rogoz, infectologist at Sanador Clinical Hospital in Bucharest. Some $27 \%$ of its population has been fully vaccinated, less than half the EU average. Rogoz sees a mix of factors to blame, among them an "overly optimistic communication strategy" by the government. Like Bulgaria, Romania's government has also been accused of failing to engage the Roma, who make up around one tenth of the population and who can be highly vaccine hesitant. ${ }^{5}$

Public authorities put themselves in a corner by dismissing the possibility of vaccine mandates or restrictions coupled with vaccinated status early on, Rogoz says. There has been a recent reversal, but, he adds, "We're probably running out of time."

Irina Hristova's name has been changed to protect her privacy.

Commissioned, not externally peer reviewed.

Competing interests: I have read and understood BMJ policy on declaration of interests and have no relevant interests to declare.

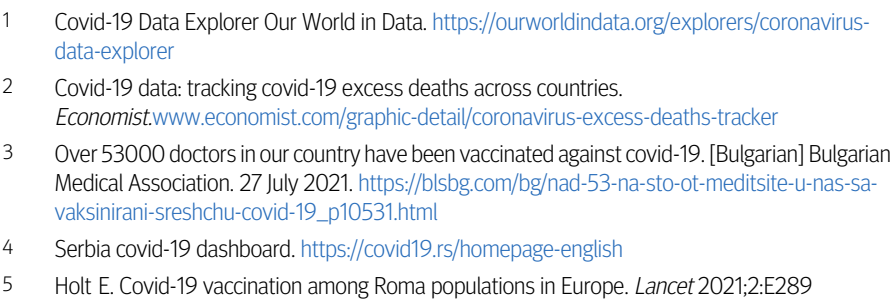

This article is made freely available for use in accordance with BMJ's website terms and conditions for the duration of the covid-19 pandemic or until otherwise determined by BMJ. You may use, download and print the article for any lawful, non-commercial purpose (including text and data mining) provided that all copyright notices and trade marks are retained. 